\title{
Application of lean six sigma methodology to improve the weight inconsistency problem of coffee powder packaging
}

\author{
Nik Alimi Nik Aziz ${ }^{1}$, Rosmaini Ahmad ${ }^{2 *}$, Shaliza Azreen Mustafa ${ }^{2}$, Tan Chan Sin $^{2}$, \\ Muhammad Shahar Jusoh ${ }^{3}$ \\ ${ }^{1}$ Faculty of Mechanical Engineering Technology, Universiti Malaysia Perlis (UniMAP), Alam Pauh Putra Campus, 02600 Arau, Perlis, \\ Malaysia. \\ ${ }^{2}$ Advanced Manufacturing System (AMS) Research Group, Faculty of Mechanical Engineering Technology, Universiti Malaysia Perlis \\ (UniMAP), Alam Pauh Putra Campus, 02600 Arau, Perlis, Malaysia. \\ ${ }^{3}$ Faculty of Applied and Human Sciences, Universiti Malaysia Perlis (UniMAP), 01000
}

\section{ARTICLE INFORMATION}

Article history:

Received: September 2, 2021

Revised: October 7, 2021

Accepted: October 20, 2021

Keywords:

Continuous improvement

Lean six sigma

Poka-yoke

Case study

Coffee manufacturing industry

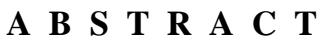

This paper presents a continuous improvement (CI) project based on the application of Lean Six Sigma (LSS) methodology. This project was carried out at the coffee manufacturing industry located in the northern area of Malaysia. The focus of this presented CI project is to improve the weight inconsistency problem of coffee powder packaging. The presented CI project was mainly guided with Six Sigma methodology of Define, Measure, Analyze, Improve and Control (DMAIC) steps, and related Lean tools applications. The step of Define summaries the overall view of CI project. In the step of Measure, the current level of Sigma based on defect per million of opportunities (DPMO) calculation was determined. Initially, $6 \%$ of rejected products were recorded, which it presents the sigma level at 3.1. In the step of Analyze, a series of team-based activities towards root cause identification was carried out. It included the applications of causeeffect (CE) analysis, possible causes prioritization, and close observations on the packaging process. In the step of Improve, the related Lean tool was proposed to improve the problem under study. In the final step of Control, related supportive actions were suggested to sustain the effectiveness of the proposed solution. There are fourteen possible causes initially identified in $\mathrm{CE}$ analysis. Based on the team's evaluation process of possible causes prioritization, four causes are collectively the most possible of root cause(s). Three close observation sessions were carried out to finalize the most possible root cause of the problem. Results strongly suggested that the high variation of coffee powder's size and inconsistency is the root cause. An improvement strategy based on Lean Manufacturing approach called 'poka yoke' is proposed. The proposed improvement strategy was then validated based on real packaging process scenario. Result shows that the proposed improvement strategy is significantly effective to solve the problem with $0 \%$ of reject product was recorded so far, where it is not only produced the product within the acceptable weight of 215 and 208 grams, but also presents the reduction of weight fluctuation that close to ideal weight of 208 grams.
*Corresponding Author

Rosmaini Ahmad

E-mail:

rosmainiahmad@unimap.edu.my

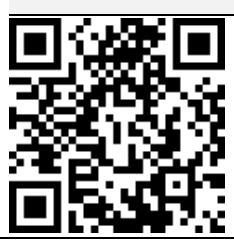

This is an open-access article under the CC-BY-NC-SA license.

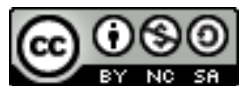

CC 2021 Some rights reserved 


\section{INTRODUCTION}

Continuous improvement (CI) has become an importance practice in the operations management of the manufacturing industry. It has been a centre of discussion since the beginning of the industrial revolution. Generally, CI is defined as a culture of sustained improvement to eliminate waste in all organizational systems and processes, involving all organizational participants [1]. In other words, the culture of CI will indirectly create a worldclass mentality of workers where they can see possible opportunities for improvement, thus contributing to business benefits.

One of the popular approaches to support, drive, and sustain the CI culture is based on the application of Lean Six Sigma (LSS). The term of LSS refers to the integration of Lean and Six Sigma philosophies [2], methodology and related tools to drive the CI project. Literature studies performed by Hill et al [3] shows that LSS application is based on the usage of Six Sigma methodology of Define, Measure, Analyze, Improve and Control (DMAIC) steps with other related Lean tools application such as Value Stream Mapping (VSM), 5 whys, etc.

According to Andersson et al. [4], if the right methodology structure of LSS is effectively integrated and applied, the CI project under consideration will significantly succeed (e.g. productivity increment with minimum costs of operations). Thus, it enabled companies to meet customer expectations even in the dynamic challenge of the global business environment. Comprehensive literature study on the topic of LSS is given in Pepper and Spedding [5].

Some recent applications of LSS approach to solving various problems in the related manufacturing industry are as follows. Adikorley et al. [6] reported a success story of LSS application in the textile industry's small- and medium-sized businesses. The application of DMAIC steps with related Lean tools such the Single Minute Exchange of Die (SMED), standardization strategy, Failure, Mode, Effect Analysis (FMEA) etc., are found to be an effective combination of tools to improve high changeover time and quality issue. From their reported CI projects, quality product variation and change over time were reduced to 37 percent. Deithorn and Kovach [7] demonstrated the success of LSS application to overcome the operational issue in oil and gas industry. Their paper claims that the iterative use of the DMAIC steps becomes a useful method to systematically addressing large problems with aggressive goals.

Singh et al. [8] presented the application of lean thinking using VSM and Six Sigma DMAIC steps. The case study of their research project was carried out at a manufacturing industry that suffered of high production lead time and Work In Progress (WIP) inventory. Their project reported significant improvement, where lead time, processing time and wastage of material movement were reduced to $14.88,14.71$ and 37.97 percent, respectively.

Sharma et al. [9] presented the application of LSS methodology to solve product defects problems in an automobile light manufacturing industry. Their research project applied DMAIC steps with Lean tools applications such as VSM, brainstorming, Pareto charts, 5S, kanban, etc. They reported the improvement at 53 percent of defects rate reduction, which improve the sigma value from 3.78 to 3.89 .

Byrne et al. [10] reported successful implementation of the LSS approach to minimize the production line downtime problem at the pharmaceutical manufacturing industry. The applications of DMAIC steps to drive their CI project, including VSM and '6-step, problemsolve' methodology, were systematically identified and effectively eliminated non-value adding (waste) activities. In overall, their CI project has contributed to downtime reduction, improving product flow, reducing the backlog, eliminating product wastage, increasing productivity and ultimately enhancing customer experience by reducing the backlog for the product to leave the factory.

In the food manufacturing industry, the recent application of LSS to improve production performance are reported by some researchers. For example, Panayiotou et al. [11] implemented LSS methodology based on DMAIC steps and Lean tools (e.g. 5 whys) applications to solve the rework problem in a food and beverage manufacturing industry. Significant improvement on process availability increment, shifts and cost reductions were recorded.

Nandakumar et al. [12] reported a study of LSS application in a food processing company. The major focus of their study is to improve the problems of bottlenecks and high defect rates that occurred at the production and packaging departments, respectively. Various techniques such as DMAIC, VSM, 5s etc. were applied in 
their case study. Several strategic suggestions were then given to improve the overall equipment efficiency and productivity and reduce production fluctuations.

This paper reported another case study based of CI project using LSS approach. The presented CI project was carried out at a local's small, medium enterprise (SME) industry of coffee manufacturing in Malaysia. Although the benefits of Lean, Six Sigma, including LSS applications to improve the performance of the food-related industry, is reported in Costa et al. [13], however number of studies is still low [14].

Furthermore, a specific application of LSS in the coffee processing/manufacturing industry is currently absent. Thus, this motivates this presented paper. The objective of this paper is to present a step-by-step process of CI by applying LSS methodology. The focused improvement area is on the packaging process of coffee powder, where some defects directly create non-value added activities and hence affect productivity. Detailed descriptions of the problem under study is given in the following sections.

This paper is organized as follows. The next section present th case study background, where related introduction of the case study's company is included. The next section is the problem statement section to precisely and concisely describe the problem's scope under consideration. The methodology section is then given to present a step-by-step process of how the CI project was carried out. The next section is results and discussion, where the detailed findings are presented based on the methodology structure described in the previous section. Finally is the conclusion section to wrap up the overall summary and contributions of this paper, some future research recommendations are also included.

\subsection{Case study background}

Company $\mathrm{Z}$ was established in 1958 and is becoming one of the local famous coffee manufacturers in Malaysia with 'Kopi Hang Tuah'. Varieties of coffee products from this company reached global markets, including Hong Kong, Australia, Thailand, Brunei, Ireland, Singapore, Britain, Vietnam and United Kingdom.

There are four main coffee manufacturing processes that practice in this company, which it starts with roasting, cooking, grinding and packaging. In the packaging process, currently, there are some different of packaging processes depends on the product specification. One of them is called the nitrogen packaging to produce 200 grams of coffee powder with brand $\mathrm{X}$. This packaging process is structured with three specific sequence of processes along it production line. The process start with sieving, follow by auger filler nitrogen packing and ended with weighing of packed product as shown in Fig. 1.

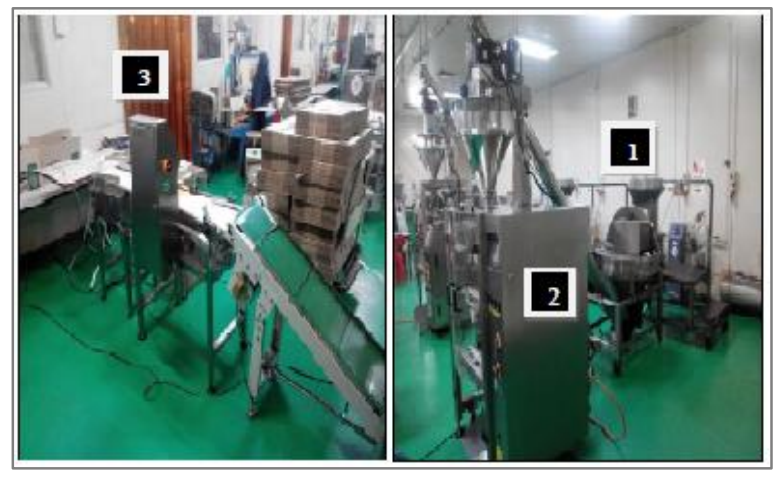

Fig. 1. Nitrogen packing process machines ( 1 is sieving machine, 2 is auger filler machine and three is weighing machine)

As shown in Fig. 1, a sieving machine is used to sieve the coffee powder from impurities before it delivers to the auger filler packing machine. The auger filler packing machine is used to perform the bag making, coffee filling, nitrogen filling, date coding and bag cutting. Finally, a weighting machine is used to record the weight of the packed product. The current production cycle time of this product is 25 packs per minute.

\subsection{Problem statement}

Fig. 2 presents the distribution of four types of defects that currently occurred at the nitrogen packaging process for the last few years. The Pareto chart indicates that the highest defect at $70 \%$ comes from packed products for weight more than 215 gram. The second highest defect is plastic broken or tear, which is $20 \%$ of overall defects. The weightless than 208 gram and plastic leakage defect contribute $7 \%$ and $3 \%$, respectively.

This Pareto chart clearly shows that the inconsistent weight (weight more than 215grams and less than 208grams) contributes $77 \%$ of the overall defects issue at the nitrogen packing process. Therefore, the focus of this CI project is to improve the problem of product weight inconsistency. 


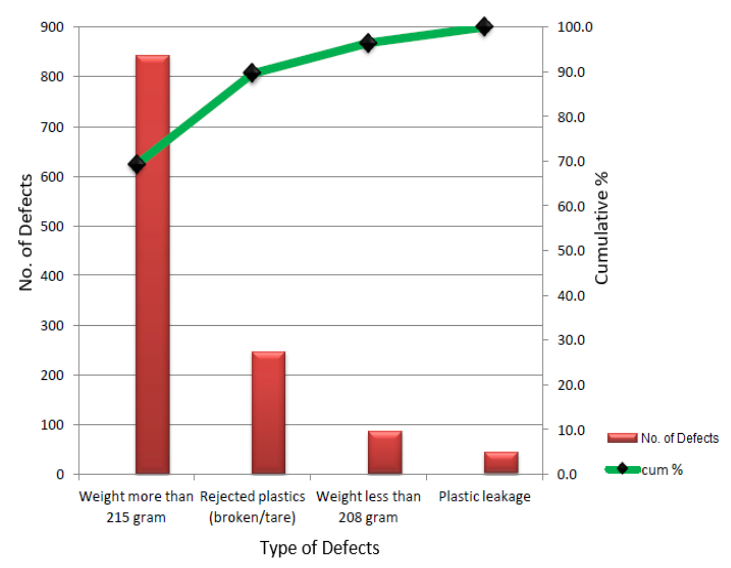

Fig. 2. Defects distribution of packed product

Specifically, the company has set the standard of the weight range of packed products: it should be between 215 grams to 208 grams (considering 7 grams is the weight of plastic packaging). In other words, the packed product without this range is considered as a rejected product. Ideally, the product weight at 208 grams is the perfect product specification intended by the process. However, the company considers the differences of the weight range at 7 grams (215 208 grams) is acceptable.

\section{RESEARCH METHODS}

The methodology applied in this CI project is based on Lean Six Sigma (LSS) approach. Fig. 3 presents the overall structure of the methodology. The first step is 'Define'. This step mainly aim to provide a precise and concise "blueprint" of the CI project. In other words, all the important information (e.g. title, objective, scope, timeframe etc.) of the project can be summarised into a platform, namely a project charter. In addition to this first step, the supplier, input, process, output and customer (SIPOC) analysis was carried out to better understand the problem under consideration. The relationship among the SIPOC elements and the key area of conflict that create the problem are possibly revealed in this analysis. An example of SIPOC analysis is given in Setiawan and Setiawan [15].

The second step is 'Measure'. In this step more detail measurements related to the problem under study was performed. The main objective of this step is to identify and measure the related parameters of the problem explicitly. In this presented CI project, the first measurement parameter is to identify the specific types of defect(s) that are worthy to solve. This can be identified by applying related descriptive statistical analysis such Pareto analysis.

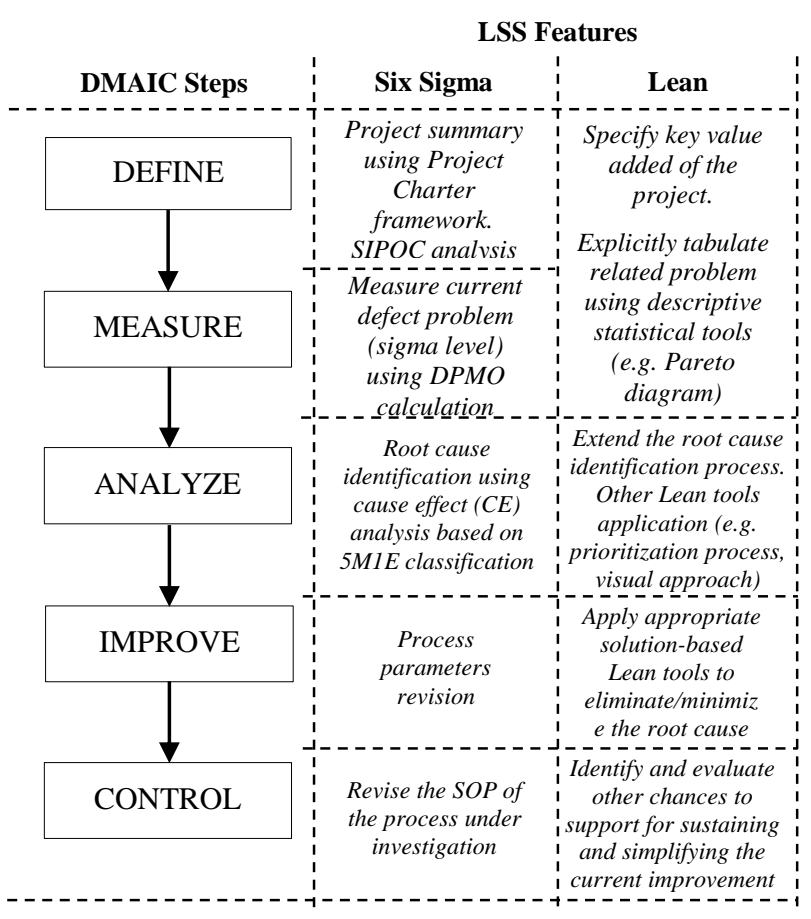

Fig. 3. LSS methodology structure

Next is to measure the performance of the process (in this study, it refers to the packaging process) that currently producing the identified defects. This can be determined based on the sigma level to indicate the status of the process. Firstly, the calculation of Defect Per Million Opportunities (DPMO) as given in Equation 1 [16], [17] is carried out. Then, Sigma level can be obtained using Equation 2 [18].

$D P M O=$

$1,000,000 *$ number of defect

number of units $*$ number of oppurtunities per units

Sigma Level $=$

$0.8406+\sqrt{29.37-2.221 * \ln D P M O}$

The third step is 'Analyze'. The main objective of this step is to identify the most possible root cause(s) of the problem. This CI project initially applied common root cause analysis using cause effect (CE) analysis. The possible causes identification are classified into 5M1E groups of cause, which they are stand for Man, Machine, Method, Material, Measurement and Environment. To ensure the generation of possible causes are closely related to the context of the problem, strategic brainstorming approach was applied among the project team's members. 
The effectiveness of root cause identification was supported with a possible cause priorityzation process to narrow down the identification of root cause(s). The process of possible causes prioritization was carried out using a voting mechanism among project team's members based on 1 (less) to 5 (strongly) evaluation scale, where based on their best of technical knowledge and experiences to what scale they believe the identified cause is the root cause of the problem? Then, the visual approach was also used to support the final verification of the identified root cause(s).

The next step is 'Improve'. This step aims to propose and verify the solution of the problem based on the identified root cause. The project team's members initially reviewed related Lean tools before finalizing the solution. The verification of the solution was carried out based on the real production process scale.

The final step is 'Control'. In this step, related adjustment on Standard Operation Procedure (SOP) was revisited. The aim of this step is to sustain the effectiveness of the proposed solution. Moreover, any related implication on the flow of production was also taken into consideration to avoid the complexity of production activities that may exist after the improvement strategy is implemented.

\section{RESULTS AND DISCUSSION}

This section presents the results and discussion based on the methodology described in the previous section.

\subsection{Define}

Table 1 shows the project charter of this CI project. The project charter contains eight key summaries of information, including the title of the project, objective, source of voice of the customer (VOC), project team members, project scope, expected financial benefit, expected customer benefit, and timeframe of the project.

In addition to the presented project charter, six key project team members are directly involved in this CI project. The project basically lead by a company's manager. The activities of CI project was planned and strategized by an appointed researcher, where the manager should approve it. The implementation of CI project's activities are strongly supported by an engineer, a line supervisor, a machine operator and a research assistant, respectively.
Table 1. Project charter

\begin{tabular}{|c|c|}
\hline $\begin{array}{l}\text { Title of } \\
\text { project }\end{array}$ & $\begin{array}{l}\text { Improvement of defect on weight } \\
\text { inconsistency }\end{array}$ \\
\hline Objective & $\begin{array}{l}\text { To produce the product, which the weight is } \\
\text { between } 215 \text { grams }-208 \text { grams. The weight } \\
\text { at } 208 \text { grams is the ideal. }\end{array}$ \\
\hline \multirow{2}{*}{$\begin{array}{l}\text { Source of } \\
\text { VOC }\end{array}$} & Highlighted by Internal customer \\
\hline & $\begin{array}{l}\text { CI team' members found this project as an } \\
\text { opportunity of improvement }\end{array}$ \\
\hline \multirow[t]{2}{*}{$\begin{array}{l}\text { Project team } \\
\text { members }\end{array}$} & $\begin{array}{l}\text { Project Leader: Company's manager } \\
\text { Project manager: Appointed researcher }\end{array}$ \\
\hline & $\begin{array}{l}\text { Technical team members: Engineer, } \\
\text { supervisor, machine operator, research } \\
\text { assistant }\end{array}$ \\
\hline $\begin{array}{l}\text { Project } \\
\text { scope }\end{array}$ & $\begin{array}{l}\text { Focus on product of coffee powder pack of } \\
\text { brand X }\end{array}$ \\
\hline $\begin{array}{l}\text { Expected } \\
\text { financial } \\
\text { benefit }\end{array}$ & Cost saving and productivity increment \\
\hline $\begin{array}{l}\text { Expected } \\
\text { customer } \\
\text { benefit }\end{array}$ & $\begin{array}{l}\text { Customers receiving the product with the } \\
\text { right and consistent weight. }\end{array}$ \\
\hline $\begin{array}{l}\text { Timeframe } \\
\text { of project }\end{array}$ & 4 months \\
\hline
\end{tabular}

Fig. 4 visualizes SIPOC diagram. The figure presents related information of the problem under study based on SIPOC framework. At this point, the figure highlights the conflict area (grey colour) of the packaging process where the defects occurred.

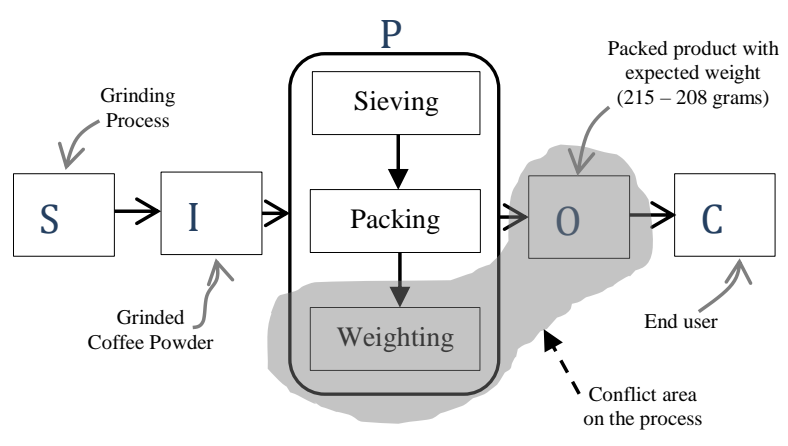

Fig. 4. SIPOC of CI project

In term of lean value, this step extends the description of the problem statement to specify the key value of the project as follows. In the perspective of business, the higher the weight (exceed predefine limit at 215grams) of products to be produced and sold to customers the lower the profit to the company. Therefore, the motivation of this CI project is to improve the consistency of product weight close to 208 grams, thus it maximizes the profit to the company. 
Another motivation of this CI project is related to the weight of product that lower than 208 grams. The product with this weight level is classified as hard-reject product, where it will go through the rework process. The packed product will be opened and repack. From Lean thinking perspective, this is non-value added activities that caused packed material (coffee powder) repeating the process of packaging. Also, the cost of plastic packaging is indirectly increased.

\subsection{Measure}

After the distribution of defects on packaging process was performed (refers problem statement section). The next process in this step (Measure) is to determine the sigma level. The current sigma level based on DPMO calculation is presented in Table 2.

Table 2 Sigma level for current defect

\begin{tabular}{ccccc}
\hline $\begin{array}{c}\text { Type of } \\
\text { defect }\end{array}$ & $\begin{array}{c}\text { Total of } \\
\text { defect per } \\
\text { week }\end{array}$ & $\begin{array}{c}\text { Average } \\
\text { production } \\
\text { per week } \\
\text { (packs) }\end{array}$ & DPMO & $\begin{array}{c}\text { Sigma } \\
\text { level }\end{array}$ \\
\hline $\begin{array}{c}\text { Weight } \\
\text { more than }\end{array}$ & 843 & 15440 & 54598 & 3.2 \\
$\begin{array}{c}215 \text { grams } \\
\begin{array}{c}\text { Weight less } \\
\text { than } 208 \\
\text { grams }\end{array}\end{array}$ & 84 & 15440 & 5440 & 4.1 \\
\hline Total & 927 & 15440 & 60039 & 3.1 \\
\hline
\end{tabular}

Generally, the total of defects at 927 represent $6 \%$ of rejected products. The sigma level for defects of more than 215 grams is 3.2 , while for less than 208 grams is 4.1. Meanwhile, the sigma level for the combination of these two types of defects is calculated at 3.1. This value of sigma level indicates that the process capability is within the indicator of "industrial average" and "noncompetitive" organization [19]. Thus, this suggested that improvement of the packaging process towards reducing the identified defects is still highly needed.

In addition, further information of product defect for weight more than 215 grams found that the rejected packs contain in average 1.5 grams per pack of extra coffee powder. By considering the average defects per week given in Table 2, there are 5,058 grams per month or 60,696 grams per year. This value indicates that if this defect can be avoided, the company can produce 282.3 (by considering 215 grams/pack) packs per year as extra productivity. Furthermore, if the packaging process can consistently produce the product with a weight close to the weight of 208 grams, thus more productivity increment can be obtained.

\subsection{Analyze}

After the current sigma level is calculated, the brainstorming among the project's team members was carried out to identify the problem's most possible root cause (s). Fig. 5 presents the distribution of the possible causes of the problem. The possible causes are classified into six causes (Man/People, Machine, Measurement, Material, Method and Environment) as described in the previous section.

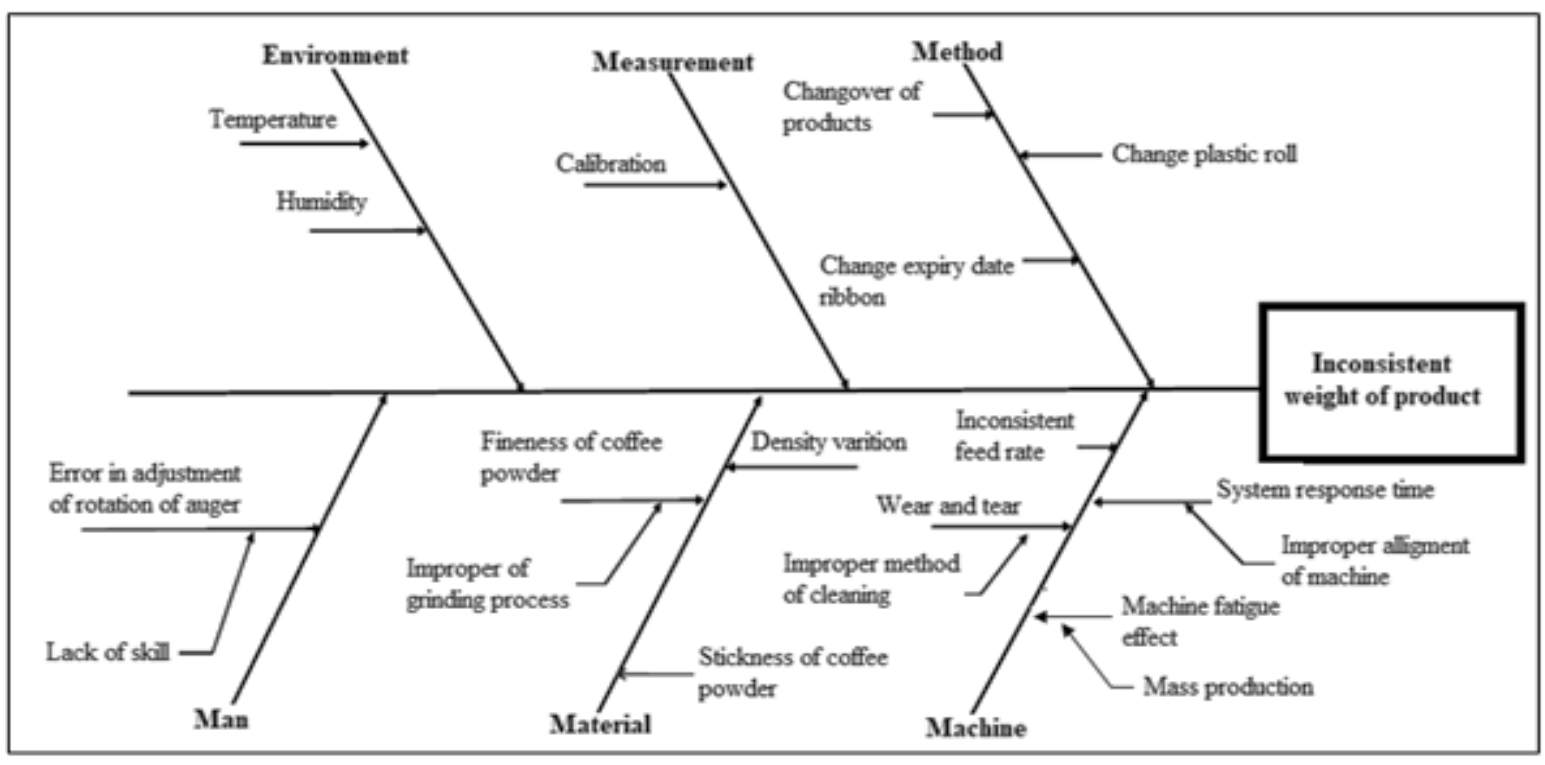

Fig. 5. Cause and effect (CE) diagram 
In total, fourteen primary causes are found that possibly contribute to the problem under study. Based on the CE diagram presented in Fig. 5 , the cause's group of Material and Method consists of three possible primary causes, respectively. Meanwhile, the cause's group of Machine, Environment, Measurement and Man consists of four, two and one possible causes, respectively.

This step (analyze) is continued with the collective evaluation process to measure the degree of possible causes. All five team members of this CI project are involved for voting. Table 3 presents the summary of the collective evaluation result. As described in the previous section, the evaluation is carried out based on a 1 to 5 scale of values. The value at 5 indicates the highest degree of evaluator's confidence that the identified cause(s) is possibly the root cause of the problem.

Table 3 Summary of collective possible causes evaluation

\begin{tabular}{|c|c|c|c|c|c|c|c|}
\hline \multirow[b]{2}{*}{ No. } & \multirow{2}{*}{$\begin{array}{c}\text { Possible causes } \\
\text { visualize in CCE } \\
\text { diagram }\end{array}$} & \multicolumn{5}{|c|}{ Voter } & \multirow[b]{2}{*}{ Avg } \\
\hline & & A & $\mathrm{B}$ & $\mathrm{C}$ & $\mathrm{D}$ & $\mathrm{E}$ & \\
\hline 1 & $\begin{array}{l}\text { Wear and tear of auger } \\
\text { screw and tube }\end{array}$ & 4 & 3 & 3 & 4 & 3 & 3.4 \\
\hline 2 & $\begin{array}{l}\text { Weighing machine } \\
\text { calibration issue }\end{array}$ & 4 & 5 & 5 & 5 & 5 & 4.8 \\
\hline 3 & Feed rate of machine & 4 & 3 & 3 & 3 & 3 & 3.2 \\
\hline 4 & $\begin{array}{l}\text { Density variation of } \\
\text { coffee powder }\end{array}$ & 4 & 4 & 5 & 4 & 5 & 4.4 \\
\hline 5 & $\begin{array}{l}\text { Fineness of coffee } \\
\text { powder }\end{array}$ & 5 & 4 & 4 & 5 & 5 & 4.6 \\
\hline 6 & $\begin{array}{l}\text { Stickiness of coffee } \\
\text { powder }\end{array}$ & 3 & 4 & 3 & 3 & 2 & 3.0 \\
\hline 7 & System respond time & 3 & 4 & 2 & 3 & 3 & 3.0 \\
\hline 8 & $\begin{array}{l}\text { Error in adjustment of } \\
\text { auger rotation }\end{array}$ & 4 & 3 & 4 & 5 & 4 & 4.0 \\
\hline 9 & Temperature & 3 & 4 & 3 & 3 & 3 & 3.2 \\
\hline 10 & Humidity & 3 & 4 & 3 & 4 & 3 & 3.4 \\
\hline 11 & Change over product & 3 & 2 & 3 & 4 & 2 & 2.8 \\
\hline 12 & $\begin{array}{l}\text { Change expired date } \\
\text { ribbon }\end{array}$ & 1 & 1 & 2 & 1 & 2 & 1.4 \\
\hline 13 & Change plastic roll & 3 & 2 & 3 & 2 & 2 & 2.4 \\
\hline 14 & Vibration of machine & 2 & 3 & 2 & 3 & 3 & 2.6 \\
\hline
\end{tabular}

The evaluation result of Table 3 highlights four specific causes (based on top four highest average values) that are possible to be the root causes of the problem. These causes are weighting machine calibration issue (4.8), fineness of coffee powder (4.6), density variation of coffee powder (4.4) and error in adjustment of auger rotation (4.0). In addition to this evaluation result, critical discussion among team members suggested that the second and third causes are related, where if the size of coffee powder is not even thus the density variation of coffee powder will exist.

The next analysis process in this step (Analyze) is to prove the extent to which these top four causes contribute to the problem. Therefore, some close observation sessions on the packaging process were carried out. In these sessions, three parameters related to the top four of the possible causes are closely monitored and recorded.

The first session is to monitor the production of 600 packs of product. The calibration activity on weighting machine (refers Fig. 1) was performed several times within this session. The calibration process is done by putting the standard bar of 200 grams on the weighting machine. Fig. 6 presents the weight distribution product in the first observation session.

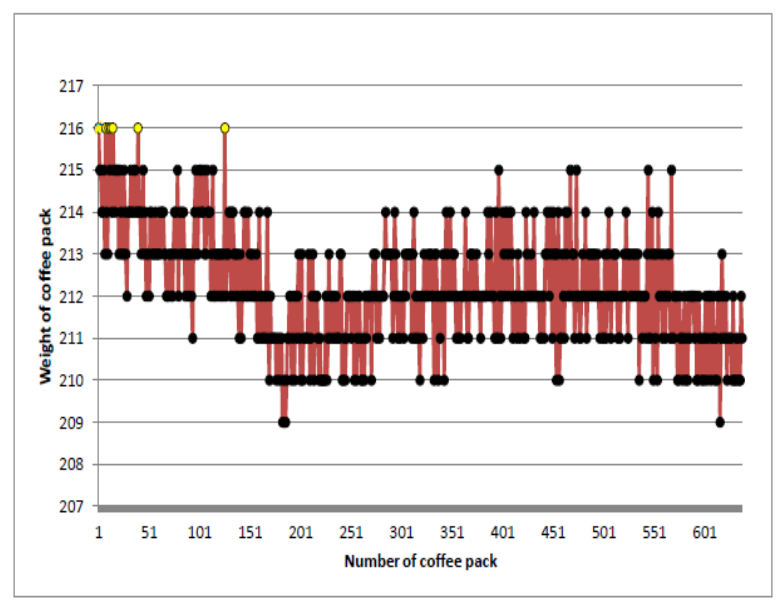

Fig. 6. First observation session of packed product

The result summary of the first observation session is as follows. There are eight rejected products recorded, all of which are classified as defect's type that exceeds 215 grams. Six times of calibration of machine weighting that was carried out for every 100 packs of the product indicates a small difference at \pm 0.3 grams. The speed rate of auger rotation on the auger filler machine (see Fig. 1) for this session has been adjusted a few times between 2266 - $2275 \mathrm{rpm}$. The samples of distribution sizes of the coffee powder used in this packaging session is shown in Fig. 7.

Meanwhile, Fig. 8 shows the weight distribution of product for 550 packs in second observation session. The result shows that there are 7 rejected product were recorded, where 6 of them is exceeded 215 grams and another one is less than 208 grams. 

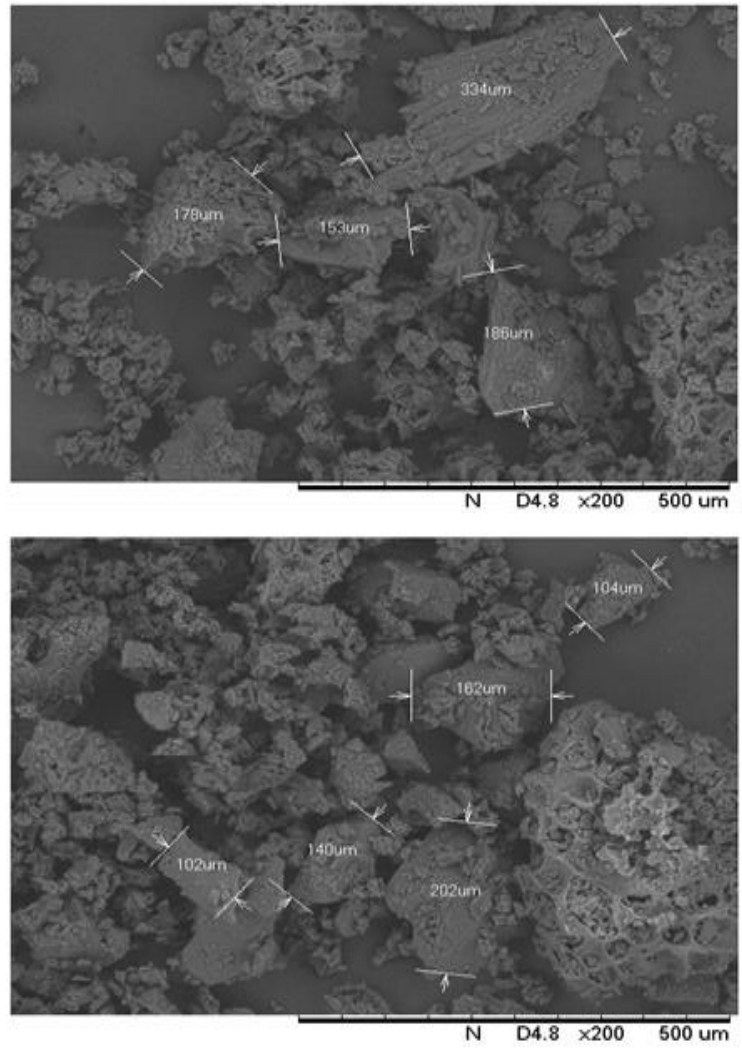

Fig. 7. Samples of size variation of coffee powder for packaging session 1

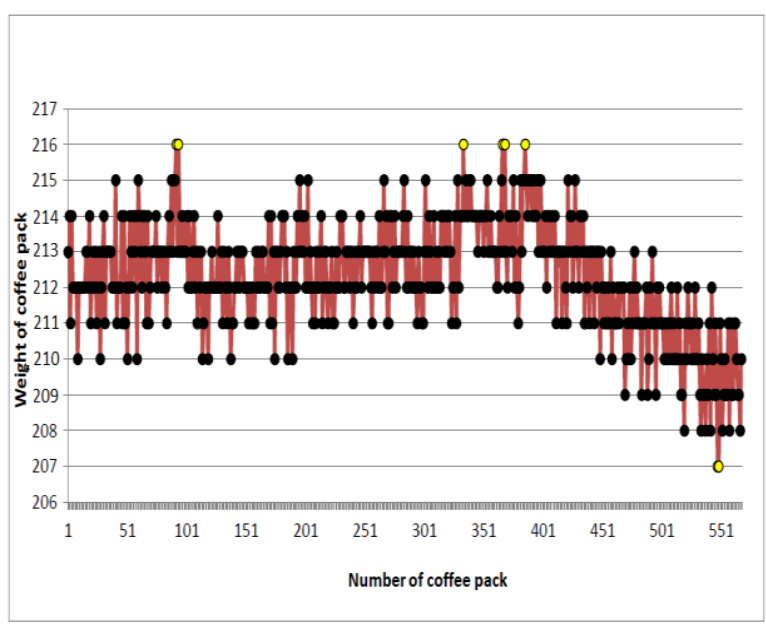

Fig. 8. Second monitoring session of packed product

In this second session, five time of weighting machine calibration was performed. The calibration indicates a small variation at value \pm 0.4 grams. The speed rate of auger rotation for this second session has been adjusted several times between 2232 - 2252 rpm. Meanwhile, Fig. 9 presents the samples of distribution sizes of the coffee powder used in this second packaging session.
Fig. 10 presents the final observation session of the production of 550 packs. There are 26 packs of product were recorded as rejected product. All of the rejected product is due to the weight less than 208 grams. Like the previous two observation sessions, calibration on the weighing machine shows a small variation at \pm 0.4 grams.
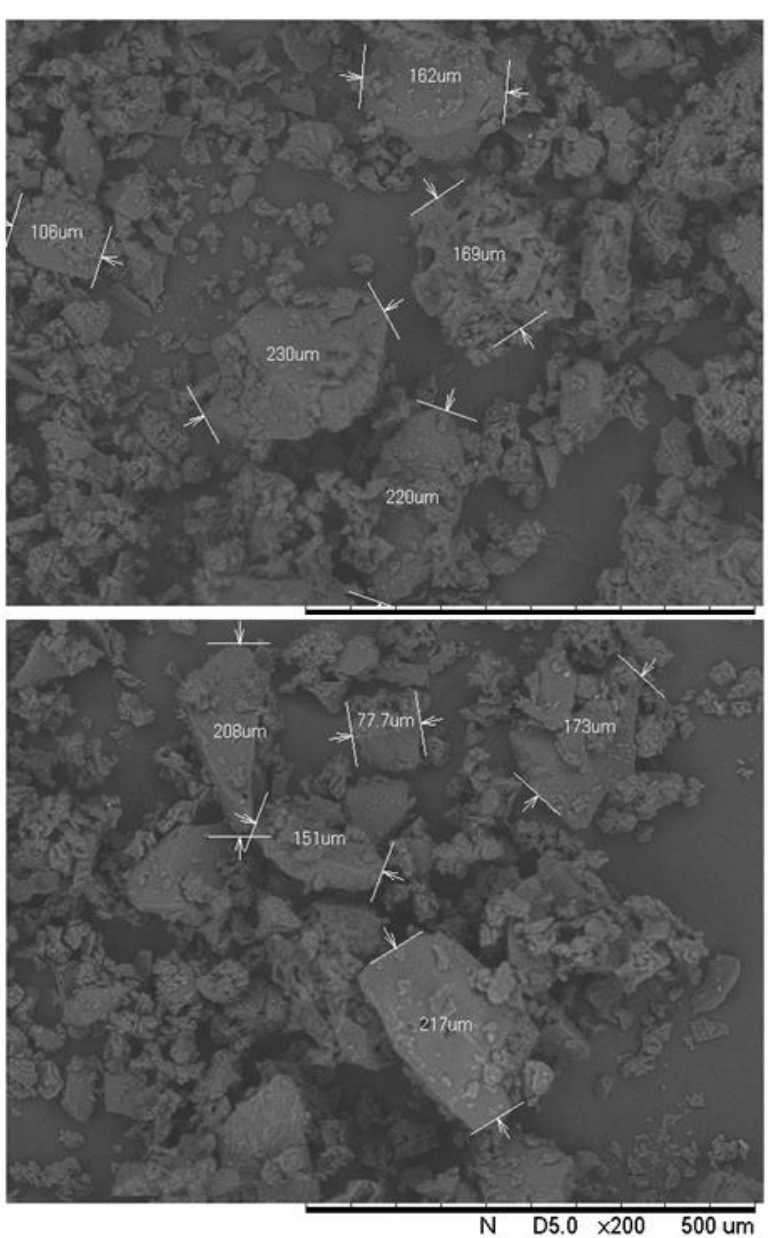

Fig. 9. Samples of size variation of coffee powder for packaging session 2

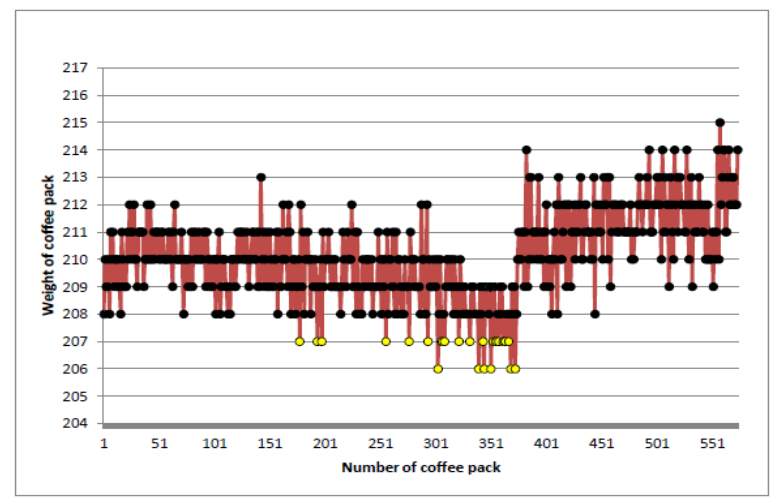

Fig. 10. Third monitoring session of packed product 
In relation to result shown in Fig. 10, the speed rate of auger rotation has been adjusted several times between 2240 - 2284 rpm. Fig. 11 presents the samples of coffee powder sizes used in this packaging session.
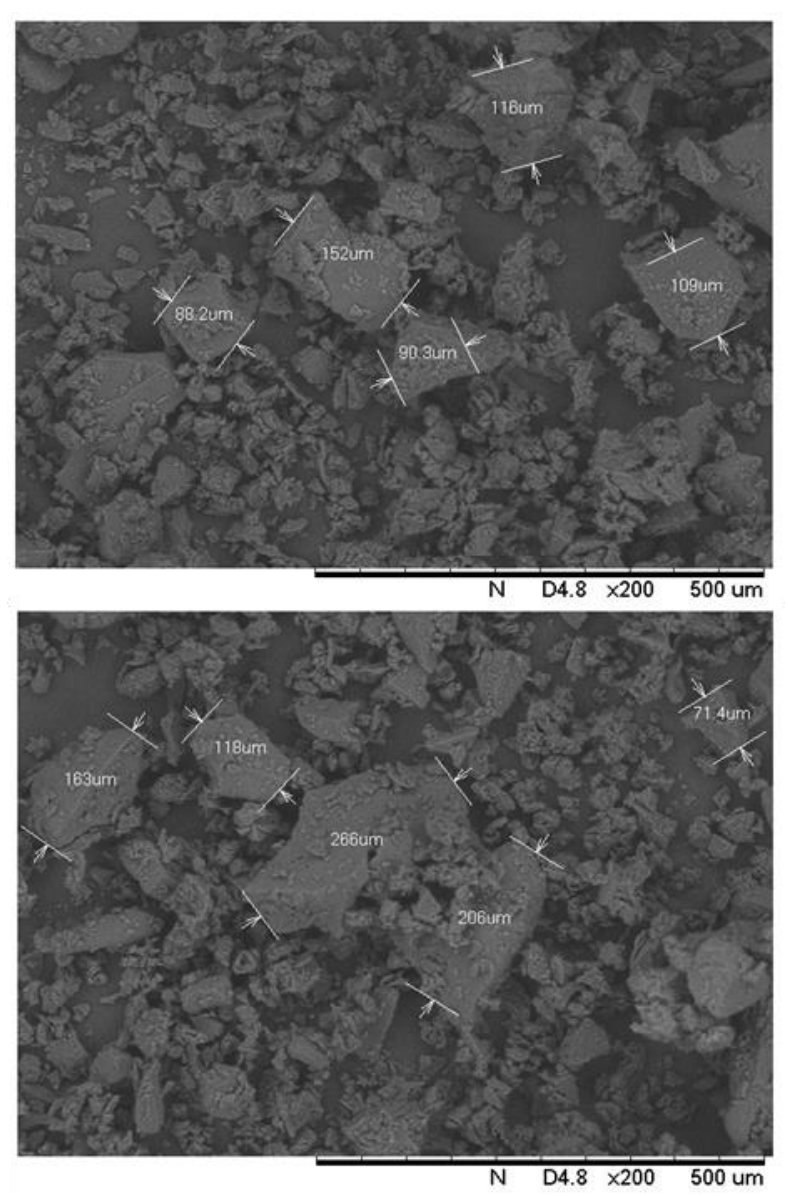

Fig. 11. Samples of size variation of coffee powder for packaging session 3

Based on these three observation sessions, several important information are found. The first is the cause of the calibration issue on the weighting machine. All of the three observation sessions clearly show no significant variation on the weighting sensitivity of the machine compared with the standard bar of 200 grams. Thus, the possible cause of the calibration issue is no longer relevant to the problem root cause.

On the other hand, the data related to the size of coffee powder and the speed rate adjustment of auger rotation has revealed significant relationship towards occurrences of defects product. The observation sessions show that the adjustment of auger rotation speed was made between 2266 - 2275 rpm, 2232 - $2252 \mathrm{rpm}$ and $2240-2284 \mathrm{rpm}$, respectively.
Critical discussion among project team members has strongly agreed that the adjustment of auger rotation speed depend on the variation size of coffee powder used. The pictures of coffee powder's samples used in these three observation sessions (refers to Fig. 7, Fig. 9 and Fig. 11) present highly variation in the size of the coffee powder. Therefore, collectively project team's members agreed to conclude that the most possible root cause of the problem under study is related to high variation of coffee powder's size. In other words, the higher the variation's size of coffee powder used in the packaging process the more frequent the adjustment of auger rotation speed should be made by machine operator. Therefore, this scenario of current practice directly cause the occurrence of product reject due to the defect types that exceed 215 grams or less than 208 grams.

\subsection{Improve}

Based on the most possible root cause identified in the previous step, a solution hypothesis is obtained. If the company can ensure the coffee powder used in the packaging process is smaller and consistent in terms of its size, adjusting auger rotation speed can be simpler with a minimum frequency of adjustment. Then, the possibility of defects occurrences will be very minimum.

One possible strategy to ensure the intended coffee powder's size before it can be packed is to enhance the sieving process. An improvement strategy is recommended related to the Lean manufacturing concept called "poka-yoke". In the manufacturing industry, the "poka-yoke" or "mistake-proofing" is a tool that is used to prevent the source of abnormalities in the production process, thus avoiding the defect to happen [20]. The related application of "poka-yoke" in the manufacturing industry is given in several studies [21]-[25].

In the context of this CI project, "pokayoke" strategy is recommended to prevent and control the size of coffee powder. In other words, only the acceptable and consistent size of coffee powder is allowed to be packed. Thus, it will make the adjustment of auger rotation speed easier compared with current practice.

The key mechanism of "poka-yoke" strategy applied in this CI project is to enhance the sieving process of coffee powder (smaller and consistent in size of coffee powder) before it 
conveys to the feeder of the auger filler machine perform the packaging process.

In order to prove the effectiveness of the proposed strategy, an experiment was carried out as follows. The enhancement of the sieving process to produce a smaller and consistent coffee powder was performed, as shown in Fig. 12.

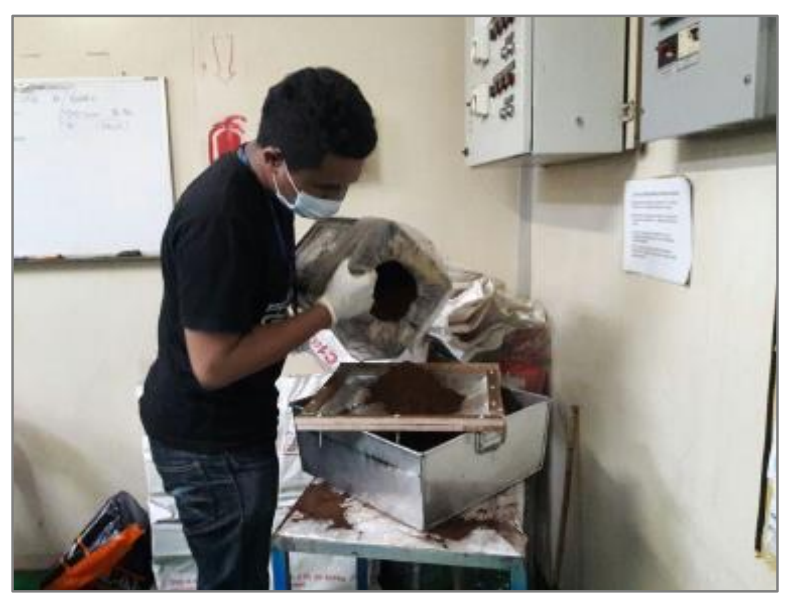

Fig. 12. Sieving of coffee powder to smaller and consistent size

On the other hand, Fig. 13 shows the pictures of coffee powder before (currently used) and after the enhancing the sieving process.

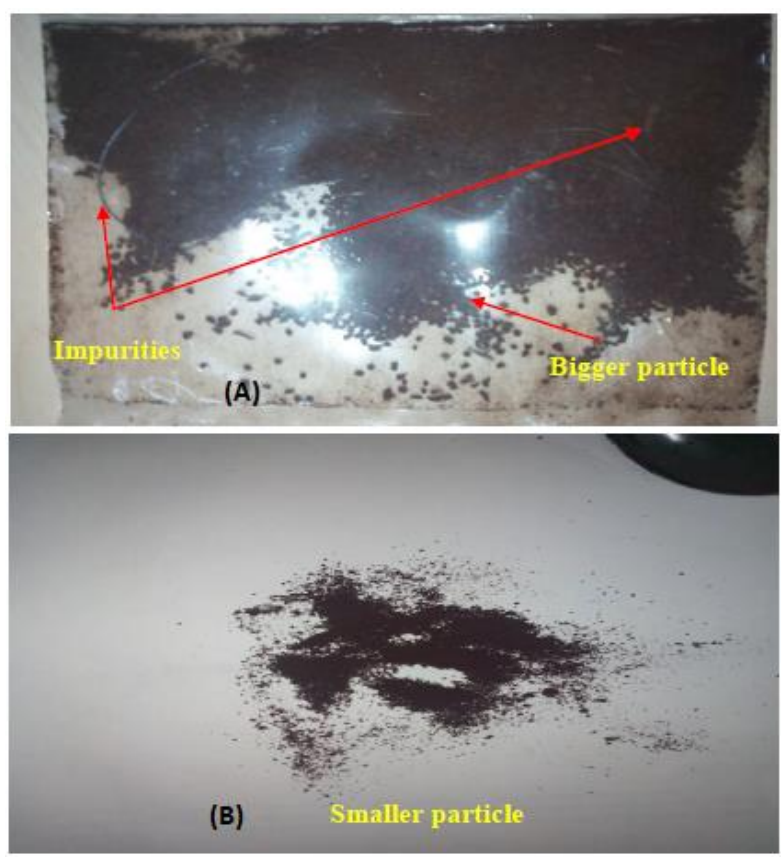

Fig 13. Comparison of coffee powder size and consistency before (A) and after (B) of sieving process enhancement

Fig. 14 presents the weight distribution of the product using the experimented version of coffee powder's size. This monitoring period recorded zero reject product $(0 \%$ reject product) for both of defect types (more than 215 grams and less than 208). The distribution pattern of product weight mostly fall between $209-211$ grams. This pattern of consistency also presents another important achievement; it reduces the fluctuation rate that is close to 208 grams.

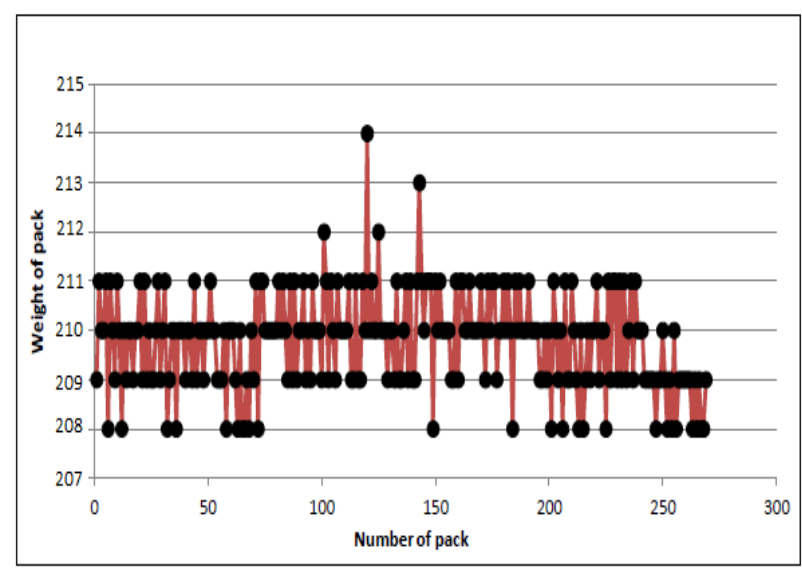

Fig. 14. Weight distribution based on experimented coffee powder

In overall, this result indicates a significant improvement based on the proposed improvement strategy by applying "poka-yoke" concept. In other words, the defects and weight consistency of the product depend highly on the coffee powder's size.

\subsection{Control}

In this step, two supportive actions are suggested to sustain the proposed improvement strategy's effectiveness described in the previous step. The first is to change the size of sieve net to be smaller than current practice. In term of the standard size of the net is out of the discussion scope of this paper. The key point of the proposed improvement strategy is to prove its effectiveness to avoid/reduce the defects product.

The second suggested action is to improve the coffee grinding process of the company. Generally, the process is to produce the grinded coffee based on a certain size of grinding machine setting. However, the samples coffee powder pictures given in Fig. $6-10$ revealed that high variation of their size. Thus, it indicates the performance of the grinding process is inconsistent. If the company is able to improve their grinding process, thus the burden of sieving process can be reduced. Therefore, the overall nitrogen packaging process can be performed in 
very smooth condition (e.g. minimize the frequency of auger rotation speed adjustment).

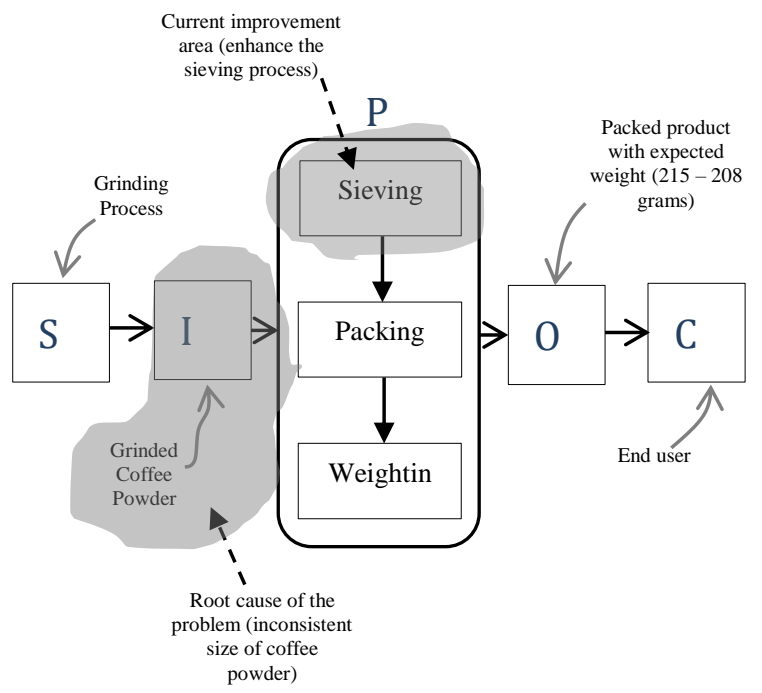

Fig. 15. SIPOC diagram (revisit version)

Fig. 15 shows the SIPOC diagram (revisit version) to visualize the area identified as the root cause of the problem. Also, the diagram highlights the targeted area for further improvement

\section{CONCLUSION}

This paper presented a case study based of CI project carried out at a coffee manufacturing industry. The reported CI project aims to improve the product's quality issue related to weight inconsistency problem. The LSS approach was applied as the main methodology to carry out this CI project. The application of DMAIC steps is the key structure of the methodology to drive the CI project. Related analysis and solution-based tools are applied, which it included DPMO calculation, $\mathrm{CA}$ analysis, possible cause evaluation process and poke yoke.

The summary of contributions of this CI project is as follows. In the step of Define, the project charter presentation gives a precise and concise view of the problem under study, including their direction. In the step of Measure, the value of Sigma based on DPMO calculation revealed that the focused problem is worthy to carry out. In the step of Analyze, a systematic root cause identification process is performed. Applications of simple qualitative (e.g. causeeffect analysis) and quantitative (e.g. possible cause evaluation) tools successfully guided the project team's member towards root cause identification. In the step of Improve, the pokayoke strategy is proposed. The poka-yoke mechanism used in this CI project enhances the sieving process to ensure the coffee powder is smaller and consistent in size before it is conveyed for packaging. Validation result found that the proposed improvement strategy have produced the weight's product within the 215 grams to 208 grams. Also, the fluctuation rate of the product's weight is reduced close to ideal weight of 208 grams. In the step of Control, related actions are suggested to support and sustaining the effectiveness of the proposed improvement strategy. There is a limitation in this current study, where the presented study is limited to prove the effectiveness of the solution proposal only. The product weight distribution as given in Fig. 14 shows the short term data to indicate the positive effect of the solution proposal but not enough to re-calculate the DPMO to measure the Sigma level after improvement.

In future research, two research works are planned. The first is to finalize the standard size of coffee powder, which is related to the size of the sieving net. The second is to improve the performance of the grinding process that supply the coffee powder. If the grinded coffee powder can be improved in terms of their size and consistency, the sieving process at the packaging will become smoother. Thus, directly producing better product quality in terms of product's weight and size consistency of coffee powder.

\section{ACKNOWLEDGMENT}

Authors wishing to acknowledge assistance and encouragement from colleagues from Faculty of Mechanical Engineering Technology, Universiti Malaysia Perlis (UniMAP). Also, top management and technical staffs of the case study company, especially in providing data and related information of the project. Finally, the authors also thank the referees for their useful suggestions to improve the quality of the article.

\section{REFERENCES}

[1] J. Singh and H. Singh, "Continuous improvement philosophy - literature review and directions," Benchmarking An Int. J., vol. 22, no. 1, pp. 75-119, Jan. 2015, doi: 10.1108/BIJ-06-2012-0038.

[2] J. H. Sheridan, “'Lean Sigma' synergy," Ind. Week/IW, vol. 249, no. 17, pp. 81-82, 2000.

Available: https://www.elibrary.ru/item.asp?id=4955 285. 
[3] J. Hill, A. J. Thomas, R. K. Mason-Jones, and S. El-Kateb, "The implementation of a Lean Six Sigma framework to enhance operational performance in an MRO facility," Prod. Manuf. Res., vol. 6, no. 1, pp. 26-48, Jan. 2018, doi: 10.1080/21693277.2017.1417179.

[4] R. Andersson, P. Hilletofth, P. Manfredsson, and O.-P. Hilmola, "Lean Six Sigma strategy in telecom manufacturing," Ind. Manag. Data Syst., vol. 114, no. 6, pp. 904-921, Jan. 2014, doi: 10.1108/IMDS-02-2014-0069.

[5] M. P. J. Pepper and T. A. Spedding, "The evolution of lean Six Sigma," Int. J. Qual. Reliab. Manag., vol. 27, no. 2, pp. 138155, Jan. 2010, doi: 10.1108/02656711011014276.

[6] R. D. Adikorley, L. Rothenberg, and A. Guillory, "Lean Six Sigma applications in the textile industry: a case study," Int. J. Lean Six Sigma, vol. 8, no. 2, pp. 210-224, Jan. 2017, doi: 10.1108/IJLSS-03-20160014.

[7] A. Deithorn and J. V Kovach, "Achieving aggressive goals through Lean Six Sigma: A case study to improve revenue collection," Qual. Eng., vol. 30, no. 3, pp. 371-388, Jul. 2018, doi: 10.1080/08982112.2018.1437448.

[8] J. Singh, H. Singh, A. Singh, and J. Singh, "Managing industrial operations by lean thinking using value stream mapping and six sigma in manufacturing unit," Manag. Decis., vol. 58, no. 6, pp. 1118-1148, Jan. 2020, doi: 10.1108/MD-04-2017-0332.

[9] A. Sharma, N. Bhanot, A. Gupta, and R. Trehan, "Application of Lean Six Sigma framework for improving manufacturing efficiency: a case study in Indian context," Int. J. Product. Perform. Manag., vol. ahead-of-print, no. ahead-of-print, Jan. 2021, doi: 10.1108/IJPPM-05-2020-0223.

[10] B. Byrne, O. McDermott, and J. Noonan, "Applying Lean Six Sigma Methodology to a Pharmaceutical Manufacturing Facility: A Case Study," Processes, vol. 9, no. 3, pp. 1-24, Mar. 2021, doi: 10.3390/pr9030550.

[11] N. A. Panayiotou, K. E. Stergiou, and V. Chronopoulos, "Implementing a Lean Six
Sigma standardized toolset in a manufacturing company: a case study," Int. J. Product. Perform. Manag., vol. ahead-of-p, no. ahead-of-print, Dec. 2020, doi: 10.1108/IJPPM-08-2020-0423.

[12] N. Nandakumar, P. G. Saleeshya, and P. Harikumar, "Bottleneck Identification And Process Improvement By Lean Six Sigma DMAIC Methodology," Mater. Today Proc., vol. 24, pp. 1217-1224, 2020, doi: 10.1016/j.matpr.2020.04.436.

[13] L. B. M. Costa, M. Godinho Filho, L. D. Fredendall, and F. J. Gómez Paredes, "Lean, six sigma and lean six sigma in the food industry: A systematic literature review," Trends Food Sci. Technol., vol. 82, pp. 122-133, Dec. 2018, doi: 10.1016/j.tifs.2018.10.002.

[14] L. B. M. Costa, M. Godinho Filho, L. D. Fredendall, and G. M. D. Ganga, "The effect of Lean Six Sigma practices on food industry performance: Implications of the Sector's experience and typical characteristics," Food Control, vol. 112, p. 107110, 2020, doi: 10.1016/j.foodcont.2020.107110.

[15] I. Setiawan and S. Setiawan, "Defect reduction of roof panel part in the export delivery process using the DMAIC method: a case study," J. Sist. dan Manaj. Ind., vol. 4, no. 2, pp. 108-116, Dec. 2020, doi: 10.30656/jsmi.v4i2.2775.

[16] R. Sharma, P. Gupta, and V. Saini, "Six sigma DMAIC Methodology Implementation in Automobile industry: A case study," J. Manuf. Eng., vol. 13, no. 1, pp. 42-50, 2018. Available: http://www.smenec.org/index.php/1/articl e/view/103.

[17] N. Nelfiyanti, A. M. Rani, and A. Fauzi, "Implementasi Six Sigma untuk Perbaikan Kualitas Produk Kiwi Paste Berdasarkan Keluhan Pelanggan," J. Sist. dan Manaj. Ind., vol. 2, no. 1, pp. 41-50, Jul. 2018, doi: 10.30656/jsmi.v2i1.609.

[18] A. Tenera and L. C. Pinto, "A Lean Six Sigma (LSS) Project Management Improvement Model," Procedia - Soc. Behav. Sci., vol. 119, pp. 912-920, 2014, doi: 10.1016/j.sbspro.2014.03.102.

[19] V. Kumar, P. Verma, and V. 
Muthukumaar, "The Performances of Process Capability Indices in the SixSigma Competitiveness Levels," 2018. Available:

http://ieomsociety.org/ieom2018/papers/5 24.pdf.

[20] M. Lazarevic, J. Mandic, N. Sremcev, D. Vukelic, and M. Debevec, "A Systematic Literature Review of Poka-Yoke and Novel Approach to Theoretical Aspects," Strojniški Vestn. - J. Mech. Eng., vol. 85, no. 7-8, pp. 454-467, Jul. 2019, doi: 10.5545/sv-jme.2019.6056.

[21] P. N. Richards, "A Study on Implementation of Poka- Yoke Technique iIn Improving the Operational Performance by Reducing the Rejection Rate in The Assembly Line," Int. J. Pure Appl. Math., vol. 119, no. 17, pp. 21772191, 2018.

Available:

https://acadpubl.eu/hub/2018-11917/2/180.pdf.

[22] E.-A. Attia, K. Khader, and O. Nada, "Mistake Proofing Cam Mechanism Through Six-sigma Process: Case Study on
Clothes Printing Machines," Int. J. Eng., vol. 32, no. 3, pp. 438-444, 2019. Available:

https://iranjournals.nlai.ir/handle/1234567 89/336622.

[23] G. Hoellthaler, S. Braunreuther, and G. Reinhart, "Requirements for a methodology for the assessment and selection of technologies of digitalization for lean production systems," Procedia CIRP, vol. 79, pp. 198-203, 2019, doi: 10.1016/j.procir.2019.02.046.

[24] D. R. Putri and W. Handayani, "Zero Defect pada Produksi Kantong Kraft melalui Metode Poka Yoke di PT. Industri Kemasan Semen Gresik," J. MEBIS (Manajemen dan Bisnis), vol. 4, no. 1, pp. 44-58, Jul. 2019, doi: 10.33005/mebis.v4i1.52.

[25] C. Rösiö, T. Aslam, K. B. Srikanth, and S. Shetty, "Towards an assessment criterion of reconfigurable manufacturing systems within the automotive industry," Procedia Manuf., vol. 28, pp. 76-82, 2019, doi: 10.1016/j.promfg.2018.12.013. 